\title{
Applying Nearpod to the Teaching Chinese as a Second Language class to Enhance Interactions and Collaborations in the Secondary Schools
}

\author{
Wurigen Zhao, ${ }^{1, *}$ \\ ${ }^{1}$ Faculty of Education, The University of Hong Kong, Hong Kong \\ ${ }^{*}$ Corresponding author email: wurigen@connect.hku.hk
}

\begin{abstract}
The quick spread of the epidemic since 2019 together with fast advancing of technology have exposed teachers to online education, including Teaching Chinese as a Second Language Classrooms. Some Chinese as a second language (CSL) teachers were reluctant to utilize technology tools in their teaching due to the lack of technological knowledge. Thus, this study designed a CSL curriculum with the lens of the TPACK framework (Technological Pedagogical Content Knowledge). Nearpod was specifically adopted as a web-based technology tool to support the teaching Chinese language due to its powerful functions provided. Nearpod allows teachers to design interactive activities in multiple ways to facilitate interactions and collaboration in the CSL learning process. This paper aimed to help Chinese teachers improve their understanding of how to effectively integrate technology into CSL teaching. Chinese teachers will develop a deeper comprehension of distance teaching from the perspectives of technology, pedagogy, and content knowledge, enhance students' deeper learning and promote interaction and collaboration in L2 class. The effective use of the technology can develop language skills in a meaningful context knowledge with the guidance of pedagogical content knowledge.
\end{abstract}

Keywords: Teaching Chinese as a Second Language, TPACK, Nearpod, Interaction, Collaboration.

\section{INTRODUCTION}

With the development of educational technology and the expansion of COVID-19 since 2019, online learning has become significantly important in meeting the new educational needs with the help of new educational tools. In order to promote student's learning experiences, educators have started to adopt different kinds of technological applications or software programs to support the teaching and learning process. For example, Nearpod is a web-based learning platform to increase collaboration and interaction in the teaching and learning process and it is becoming increasingly popular amidst the new online learning trend. Previous research on the application of Nearpod generally focused on applying it in different subjects such as Maths, Science, and Literature. However, few studies attempted to investigate the possibility of integrating Nearpod to the L2 classrooms, specifically in Chinese as a second language (CSL) classrooms. Thus, guided by the Technological Pedagogical Content Knowledge (TPACK ) framework, this study aimed to develop a Nearpod integrated CSL lesson for the purpose of enhancing interaction and collaboration between teachers and students in the CSL classroom.

\section{TPACK FRAMEWORK}

In order to deepen teacher's knowledge, Mishra and Koehler [1] introduced the framework: Technological Pedagogical and Content Knowledge (TPACK), which has quickly become an essential component of teacher's knowledge and pre-service training. This framework has three main components: (1) Technological knowledge (TK)- teacher's knowledge about basic understanding of technology concepts and operations; (2) Pedagogical knowledge (PK)- teacher's knowledge about teaching and learning strategies; and (3) Content knowledge (CK)teacher's knowledge about subject matter knowledge. The knowledge in these three areas is not separated from each other but interrelated in the teacher's works. The productive technological integration into teaching needs to consider all three components not in isolation but 
within the system's complex relationships defined by the three key elements [1]. Every two areas of the three elements overlap in pairs to create: (1) Pedagogical Content Knowledge (PCK) [2], (2) Technological Content Knowledge (TCK), or (3) Technological Pedagogical Knowledge (TPK). Figure 1 displays the overlapping relationship of three areas of knowledge form Technological Pedagogical and Content Knowledge (TPACK). (see Figure 1)

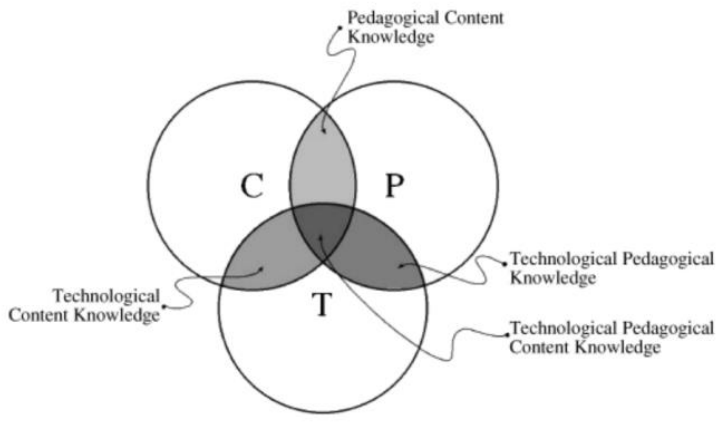

Figure 1 TPACK Framework [1]

CSL teachers specifically need to think deeper in how to effectively and efficiently integrate technology as an essential component of their teaching to enhance teacherstudent interaction and collaboration, instead of using it just as a tool of displaying content. In addition, the integration of technology in a well-design curriculum or lesson can play as a role of a productivity tool, communication tool, research tool, problem-solving and decision-making tool [3] to support the CSL teaching and learning.

Nearpod, as a popular online learning platform, was adopted in this designed CSL lesson with other digital tools to enhance students' collaboration and understanding of Chinese language learning. This lesson reflects students' collaborations and interactions and promotes more profound thinking skills and ability in teaching Chinese as a second language (TCSL) context. The subject of this lesson is CSL, and the topic is about the past tense and conjunctions. This lesson targeted tenth-grade students who are required to: (1) learn basic knowledge about the Chinese dynasties; (2) understand the cause and effect of specific events, (3) compare the similarities and differences between dynasties, and (4) write down a short reflective passage. $10^{\text {th }}$ grade students in CSL classrooms are also required to be able to complete a collaboration task about concept mapping on the internet. In the next sessions, I will demonstrate the details of this CSL lesson from the three aspects: technology, subject matter, and pedagogy.

\subsection{Technology Perspective-Introducing Nearpod}

Nearpod is a free online platform (https://www.nearpod.com/) that is accessible using electronic tools like computers, laptops, tablets, and phones. It is available in the IOS, Android, and in nearly all computer-based operating systems like macOS or Windows, which are convenient for teachers to create interactive lessons and for students to access the contents. Furthermore, both students and teachers can get access to the Nearpod lesson simultaneously simply using a web browser that have internet connection. Students have the option of choosing self-paced learning at their convenient time. Nearpod also provides a secure online learning environment for students. Teachers are able to share a series of codes (see Figure 2) randomly created by the Nearpod via Link, Email, Google Classroom, Remind, and Microsoft Teams with students. Only students who get invited will have access to the shared lesson.

\section{Join at join.nearpod.com or in the app

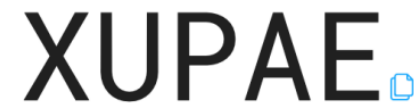

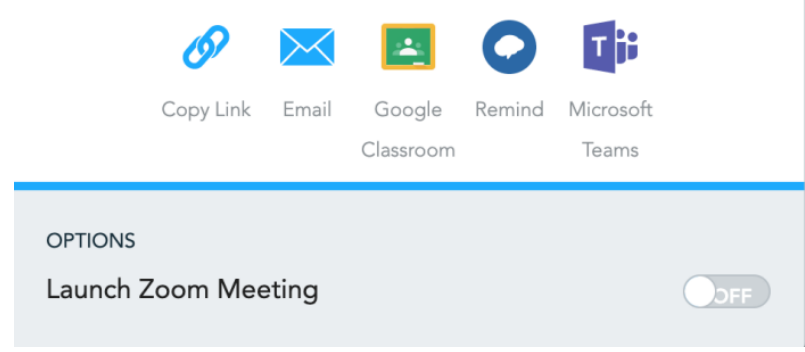

Figure 2 Example of Nearpod lesson code

Students will be able to join the class with the provided code to access the materials through their own selected devices. Students will only participate in the activities their teacher allowed and provided access to. During the teaching process, teachers can view the group activities from their digital devices. When switching to presentation mode, there are options for teachers to either design their own slides within the application itself or to upload an existing PowerPoint, PDF or image files (with a user-friendly drag and drop facility) [4]. Teachers also have other options such as adding various content via the features provided. Nearpod also provides various interactive features such as quizzes, collaborative board, and open-ended questions.

Teachers are able to create a lesson easily via the button "Add Content" (see Figure 3) and choose one category from a range of option: slide, Video, Web Content, Nearpod 3D, Simulation, VR Filed Trip, BBC Video, Sway, Slideshow, Audio, PDF Viewer. Teachers can select one or more according to what content they want to display to their students. For instance, YouTube or other videos can be added by clicking "Video"; URL links can be added to their existing "Web Content" to support teachers with more online resources they consider 
relevant to their lesson; interactive 3D pictures can be added to the lesson by clicking "Nearpod 3D."

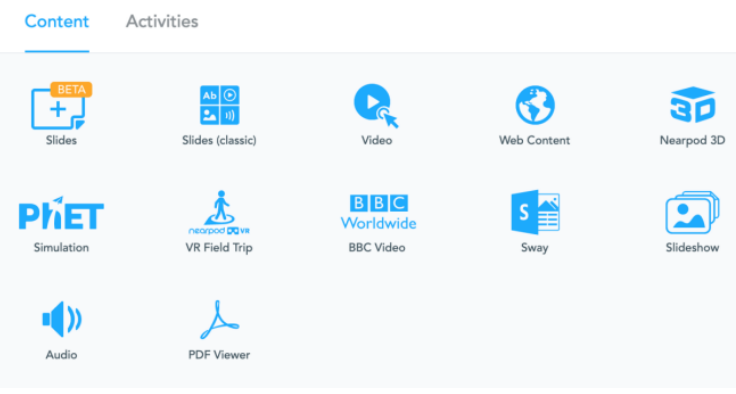

Figure 3 Add Content

There are also many options within the "Add Activities" (see Figure 4) feature such as Time to Climb, Drag \& Drop, Open-Ended Question, Matching Pairs, Quiz, Flipgrid, Draw it, Collaborative Board, Poll, Fill in the Blanks, Memory Test. Teachers can choose "Quiz" to create multiple-choice questions as a formative assessment or a summative assessment, and students are provided the chances to discuss, collaborate, post their responses, and participate in "Collaborate board." Teachers will be able to view answers from certain students, but it is anonymous on the student's end, which allows students to express their ideas bravely.

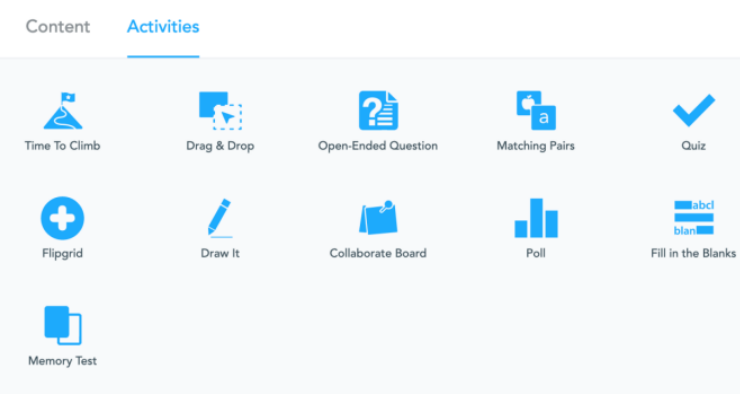

Figure 4 Add Activities

With Nearpod, teachers can create a participatory culture and collaborative learning community with technology in the classroom [5]. Students are given more opportunities to express their ideas and improve their speaking, reading, listening, and writing skills. Various technological activities are also designed in Nearpod for students. The uses of "Collaborate Board" and "Openended Question" offer students authentic ways to practice their writing so that their writing ability can be improved. Meanwhile, these two technological activities give students more chances to discuss and interact with each other so that students' communication and collaboration skills can be practiced and improved. Moreover, "Matching Pairs" and "Drag \& Drop" offer the teacher and students more opportunities to evaluate and regulate the learning progress of the lesson. Teachers can provide feedback timely to students when they are doing the practices and reschedule the teaching plan during the class if necessary.
Meanwhile, students' self-directed learning ability and problem-solving skills can also be developed. Students need to establish learning goals by themselves, plan how to solve a problem, and reflect on their learning outcomes [5]. In addition, videos and websites are utilized as cognitive tools in the lesson [3]. Students will analyze the information about conjunctions and relative pronouns collected from the internet and the videos and then use the information to research, communicate with their peers, and solve the problems. Therefore, students' problemsolving ability, communication skills as well as critical thinking ability can be developed. Once these activities are finished, teachers can see a report generated automatically from Nearpod including students' responses to the questions. This enables teachers to monitor students' participation, engagement, and understanding of the content knowledge through the activities teachers designed. Then it allows teachers to provide students timely feedback to reteach information that has been misunderstood according to the concrete evidence.

\subsection{Pedagogical Perspective}

In order to maximize the learning outcome, various pedagogical strategies are also applied in this designed CSL lesson. First, teachers can use the feature of group work in Nearpod to facilitate students' collaborative learning. In the group work, students need to do research collaboratively to complete a concept map illustrating the interrelationships and connections between the different ancient Chinese dynasties and then present their discoveries orally to the audience. During the process, students discuss and share their ideas, stimulating their higher-level thinking. Every group member will contribute to the group's success and have an equal opportunity to do their best [6].

Meanwhile, group work will also be helpful to create a low affective filter for students so that they can build their self-confidence and be motivated to participate in the class [7]. Students will feel more confident in group work since they can help each other and solve the problems together in a relaxed environment. In addition, scaffolding and differentiation strategies are also applied in the classroom. Teachers can use the pre-assessments as bridging to relate students' prior knowledge to the new topic at the beginning of the class [8]. Meanwhile, the videos, pictures, and materials on websites are great resources as scaffolding to help students understand the new concepts and be more active to participate in the activities. Moreover, students can choose to select one of the VR field trip pictures they are most interested in and use the trip as a resource to present their descriptions in the target language. The class will be more engaging, and the learning environment will be more active under such a strategy. 
In addition, teachers can create formative assessments and summative assessments in Nearpod for this designed lesson to monitor and reflect on students' learning progress. The "open-ended question" activity with the use of the "3-2-1" Bridge strategy [9] in Nearpod can be beneficial for students as the formative assessment, which requires students to write down three topic-related Chinese words or phrases, two sentences about ancient Chinese culture, and one question they are curious about before the group work activity. This routine can be repeated at the end of the instruction to write down three things they learned from the lesson, two things they liked or two interesting facts about the lesson, and one question they still have about it.. These steps enable teachers to see how readily learners synthesize and integrate new information into their thinking on the topic [9]. Using such a pedagogical strategy will allow students to review the lesson, check their understanding, and provide feedback to move students forward [10].

Furthermore, features in Nearpod such as "Matching Pairs" and "Drag and Drop" are used for students to find the connections between concepts or similarities and differences between events in Chinese dynasties, which requires students apply reading and critical thinking skills. Teachers will be able to use it as a formative assessment to monitor students' learning progress during the lesson [10]. Students can also use it to evaluate their own learning progress and regulate their learning goals. The collaborative group task designed links to a Sway, which instructs students how to use the Coggle as a mapping tool to complete a concept map activity. In the group work activity, the materials and products are differentiated [11]. Students can explore inquiry-based learning in small groups to research the basic knowledge about China's dynasties and investigate the inner relationships across the events and concepts in the concept mapping activity. Students can choose and compare the dynasties they want and investigate culturalrelated questions they formulated through their procedures. They also need to think critically, look up the words or phrases online if necessary, compare the differences between dynasties, and solve the problems. During the small group activity, teachers will be able to intervene in each small group with effective feedback modelled into three critical questions: Where am I going? (What are the goals?), How am I going? (What progress is being made toward the goal?), and Where to next? (What activities need to be undertaken to make better progress?) [12]. Students' focus on the content may differ, which stimulating divergent thinking to solve the problems through collaborative communication and thinking. This task asks students to interact in the class more actively. After completing the concept mapping assignment in small groups with their team members, students will need to present their reflections about the concept map to the whole class in Chinese.
Moreover, summative assessments are also used in this designed lesson, which provides evidence of students' learning outcome [10]. At the end of the class, the activities like "Fill in the Blanks" and "Quiz" can be used to design as summative assessments to check students' learning outcomes of this lesson. These assessments are designed to check students' understanding and utilization of the expression of the past time. Using summative assessments, teachers will have a clear sense about students' understanding and adjust the teaching to help students move the learning forward.

\subsection{Content Perspective}

The teaching of content knowledge, specifically in traditional physical classrooms, is provided by teachers. Specifically in CSL classrooms, students usually are busy memorizing the facts of the subject matter without connections. However, language learning should be input meaningfully and acquired in a contextualized background, instead of just using rote memorization strategy. The effective use of technology benefits the teaching and learning process and develops students' higher-order thinking with the connection between Chinese language context and authentic life. Different kinds of tasks are applied in this lesson to meet the learning goals. At the beginning of the lesson, an openended question activity allows students to describe what they did yesterday and use a word or a phrase to connect their ideas. Students will be asked to type their responses in the answer box. The task relates to students' prior knowledge, which utilizes their lived experiences and stimulates their interests [13]. According to the cognitive theory, relating the new knowledge to prior knowledge will help students comprehend new information easier[14].

Meanwhile, a research task is designed specifically for students to learn new content. Students need to do the research online, discuss several questions with their peers and share their ideas on the "Collaboration Board". Students will use symbolic forms from the visual media as cognitive tools to help them learn [15]. In this task, students use videos and websites as visual and audio aids to help them understand how to express past tense using time words, adverbs, or auxiliary verbs. Moreover, they are prompted to think about some questions such as using conjunctions and which position to place the time phrases or auxiliary verbs and discuss with their peers. This task provides students with more learning resources, enhances their understanding of conjunctions and past time expressions, and stimulates their critical thinking.

In addition, the design of a high-cognitive demand task for students aims to meet the learning goals further. Students need to take a VR field trip in Nearpod about ancient China's architectural landscapes in Tang and Song dynasties, observe the details in the buildings, and describe it using conjunctions and time phrases in which 
they learned from the videos and web resources. This session also wants to stimulate students' interests in Chinese ancient culture. In order to respond to the task, students will need to master the usages of conjunctions and time phrases expressions and know how to use them in Chinese writing. A lesson will also be planned to support students in using the language [16]. Thus, a collaborative task is designed to meet the high cognitive demands to achieve the learning objectives further. Students will need to click into a new web page linking to Sway, which is an interactive online platform from Microsoft Office, to create and share interactive reports, stories, presentations, and more. Sway will provide instructions for students on how to do concept mapping activity on Coggle, an online tool for creating and sharing mind maps. Concept mapping allows students to build new and meaningful knowledge links by active engagement [17]. Students will be divided randomly into groups to do a concept map activity on the incomplete map in this session. Each Coggle links to an external topic-related educational website for students to research and completes the mapping assignment. The design of this section is to provide students with chances to explore meaningful research to foster practical skills for future use. Concept map activity can make them curious and motivate them to learn more about the subject [18]. This task aligns with the learning goals and gives students opportunities to make meaningful output and apply what they have learned from the Chinese cultural context.

\section{DISCUSSION}

Nearpod is very helpful for online interactions and student engagement since its various features provide (1) highly effective feedback from students to teachers; (2) a variety of formative and summative assessment options, and (3) a great variety of choices for content display. Some students who are usually reluctant to speak out in front of the audience in the traditional physical CSL classrooms will be provided with more alternative opportunities to pose questions anonymously without too much pressure. It is an excellent way for teachers to encourage learners to use their digital devices for active online learning, instead of just using their digital tools as social media or entertainment. Some Chinese teachers acknowledge that online educational tools like Nearpod enhance effective learning and improve collaboration and interaction in teaching. It provides teachers with timely updates of students' participation in accessing many online videos and web resources. Moreover, with Nearpod, Chinese teachers are more willing to apply technology in both online teaching and face-to-face teaching. Only few Chinese teachers are reluctant to employ technology in their teaching because they did not receive enough training for how to effectively applying it in their classrooms. Hence teacher training with the TPACK framework in L2 classes is crucial and critical for the further uses of technology in CSL context.
Hopefully, this will provide some implications for future teachers and educational researchers. Especially while teachers are designing CSL lessons, not only should they integrate technological knowledge into CSL class to facilitate language skills, but also to boost other practical skills in a meaningful context at the same time. This needs Chinese teachers to take deeper consideration in L2 classrooms.

\section{CONCLUSION}

This study developed a technology integrated CSL curriculum with Nearpod for secondary school age students with the guidance of the TPACK framework. Even though the history of integrating technology into curriculum is not new, it is not as widely used in L2 classrooms specifically in CSL classrooms. I hope the designed curriculum in this study can show as a starting point to motivate more CSL teachers to integrate technology organically into their classroom. Despite Nearpod's various benefits in promoting students' Chinese language acquisition, it has some limitations. For example, Nearpod can be challenging for Chinese teachers to supervise students' character writing. CSL teachers usually expect students to write Chinese characters, which is always a vital teaching goal in CSL classrooms. Typing on the keyboard in the Nearpod does not provide hand-writing opportunities, but character writing can be implemented in a paper-pen environment.

\section{REFERENCES}

[1] Mishra, P., \& Koehler, M. J. (2006). Technological pedagogical content knowledge: A framework for teacher knowledge. Teachers college record, 108(6), 1017-1054.

[2] Shulman, L. S. (1986). Those who understand: Knowledge growth in teaching. Educational researcher, 15(2), 4-14.

[3] Niess. M.L., Lee, J.K., \& Kajder, S.B. (2008). Guiding learning with technology (Chapter 1). Hoboken, NJ: John Wiley.

[4] Burton, R. (2019). A review of Nearpod-an interactive tool for student engagement. Journal of Applied Learning and Teaching, 2(2), 95-97.

[5] Melly, Christina. (2018). "Can we blog about this?": Amplifying Student Voice in Secondary Language Arts. English Journal, vol. 107, no. 3, 2018, pp. 12 18.

[6] Slavin, R. E. (1995). An introduction to cooperative learning. In cooperation learning: Theory, research, and practice (2nded., pp.13).7 
[7] Richards, J. C., \& Rodgers, T. S. (2001). Approaches and methods in language teaching (2nd ed.). Cambridge University Press.

[8] Walqui A. (2006). Scaffolding instruction for English language learners: A conceptual framework. International Journal of Bilingual Education and Bilingualism, 9 (2).

[9] Ritchhart, R., Church, M., \& Morrison, K. (2011). Making thinking visible: How to promote engagement, understanding, and independence for all learners. John Wiley \& Sons.

[10] Black, P., \& Wiliam, D. (2009). Developing the theory of formative assessment. Educational Assessment, Evaluation \& Accountability, 21(1), 531 .

[11] Borja L. A. \& Soto S. T. \& Sanchez T. X. (2005). Differentiating instruction for EFL learners. International Journal of Humanities and Social Science, 5(8(1)):30-36.

[12] Hattie, J., \& Timperley, H. (2007). The power of feedback. Review of educational research, 77(1), 81-112.

[13] Cercone, James. (2017). "Standing at the Crossroads": Content Creation in the 21stCentury English Classroom. English Journal, vol. 106, no. 3, 2017, pp. 25-31.

[14] Myles, F., Marsden, E., \& Mitchell, R. (2013). Second language learning theories (3rd ed.) Routledge.

[15] Salomon, G., \& Perkins, D. (2005). Do Technologies Make Us Smarter? Intellectual Amplification With, Of, and Through Technology. In Intelligence and technology (pp. 95-110). Routledge.

[16] Zwiers, O'Hara, Pritchard. (2014). Chapter 1: Framing the Teaching of Academic Language and Disciplinary Literacy. Common Core Standard in Diverse Classrooms. Stenhouse Publishers, Portland, Maine.

[17] Martin, \& Davies. (2010). Concept mapping, mind mapping and argument mapping: what are the differences and do they matter?. Higher Education, 62(3) (September 2011), 279-301

[18] Van, Drie, Jannet, Van, Boxtel, \& Carla. (2003). Developing conceptual understanding through talk and mapping.Teaching History, March 2003, No. 110, Communicating History (March 2003), 27-31 